\title{
REMOVAL OF METHYL RED FROM AQUEOUS SOLUTION BY ACTIVATED CARBON PREPARED FROM THE Annona squmosa SEED BY ADSORPTION
}

\author{
T. Santhi ${ }^{* 1}$, S. Manonmani², T. Smitha ${ }^{1}$ \\ ${ }^{1}$ Department of Chemistry, Karpagam University, Coimbatore-641021, India \\ ${ }^{2}$ Department of Chemistry, PSG College of Arts and Science, Coimbatore-641021, India
}

Received 17 November 2009; received in revised form 5 May 2010

\begin{abstract}
The use of low-cost, locally available, highly efficiencient and eco-friendly adsorbents has been investigated as an ideal alternative to the current expensive methods of removing dyes from wastewater. This study investigates the potential use of activated carbon prepared from the Annona squmosa seed for the removal of methyl red (MR) dye from simulated wastewater. The effects of different system variables, adsorbent dosage, initial dye concentration, $\mathrm{pH}$ and contact time were investigated and optimal experimental conditions were ascertained. The results showed that as the amount of the adsorbent increased, the percentage of dye removal increased accordingly. Optimum $\mathrm{pH}$ value for dye adsorption was 4.0. Maximum dye was sequestered within 50 min of the start of every experiment. The adsorption of methyl red followed the pseudo-second -order rate equation and fits the Langmuir, Freundlich, Dubinin-Radushekevich (D-R) and Tempkin equations well. The maximum removal of MR was obtained at $\mathrm{pH} 4$ as $82.81 \%$ for adsorbent dose of $0.2 \mathrm{~g} / 50 \mathrm{~mL}$ and $25 \mathrm{mg} \mathrm{L}^{-1}$ initial dye concentration at room temperature. Furthermore, adsorption kinetics of MR was studied and the rate of adsorption was found to conform to pseudo-second -order kinetics with a good correlation $\left(R^{2}>0.99\right)$ with intraparticle diffusion as one of the rate determining steps. Activated carbon developed from the Annona squmosa seed can be an attractive option for dye removal from diluted industrial effluents since test reaction made on simulated dyeing wastewater showed better removal percentage of MR.
\end{abstract}

Keywords: Annona squmosa, Adsorption, Wastewater, Methyl red, Kinetics, Activated carbon

DOI:10.3329/cerb.v14i1.3767

\section{Introduction}

Industrial effluents are one of the major causes of environmental pollution because effluents discharged from dyeing industries are highly colored with a large amount of suspended organic solid [1]. Untreated disposal of this colored water into the receiving water body either causes damage to aquatic life or to human beings by mutagenic and carcinogenic effect. As a matter of fact, the discharge of such effluents is worrying for both toxicological and environmental reasons $[2,3]$.

Conventional wastewater treatment methods for removing dyes include physicochemical, chemical and biological methods, such as coagulation and flocculation [4], adsorption [5], ozonation [6], electrochemical techniques [7], and fungal decolonization [8]. Among these methods adsorption has gained favour in recent years due to proven efficiency in the removal of pollutants from effluents. Activated carbon, as an adsorbent has been widely investigated for the adsorption of dyes [9], but its high cost limits its commercial application. In recent years, there has been growing interest in finding inexpensive and effective alternatives to carbon, such as rice husk [10], chitin [11], orange waste [12], lemon peel [13], granular kohlrabi peel [14],raw barley straw [15], eggshell [16], Ricinus communis [17].

\footnotetext{
* Corresponding author, Email:ssnilasri@yahoo.co.in;
}

Phone: +9104222401661; Fax: +9104222611146
Annona squmosa is a commonly available hedge plant, which is used in fencing property perimeter in Kenerapallam, Palaghat Dt, Kerala. Foliage of the plant is thick and fruits are in abundance during the session. The inner core of the ripe fruit is delicious and of nutritive value and commonly consume. After consumption, the seeds are discarded has they are nonedeble. Since the Annona squmosa seed is available free of cost, only the carbonization of its involved for the waste water treatment. Therefore the main objective of this study was to evaluate the possibility of using dried Annona squmosa seed to develop a new low -cost activated carbon and study its application to remove methyl red from simulated wastewater. Granulized Annona squmosa seed was previously investigated to adsorb cationic dyes [18]. Systematic evaluation of the parameters involved, such as $\mathrm{pH}$, adsorbent dose, adsorbent particle size, initial dye concentration and time.

\section{Materials and Methods}

\subsection{Preparation of activated carbon from the Annona squmosa seed (CAS)}

The Annona squmosa seed was air-dried and powdered in a grinder. It was soaked in concentrated $\mathrm{H}_{2} \mathrm{SO}_{4}$ for 12 hours and washed thoroughly with distilled water till it attained neutral $\mathrm{pH}$ and soaked in two percent $\mathrm{NaHCO}_{3}$ overnight in order to remove any excess acid present. Then the material was washed with distilled water and dried at $110 \pm 2^{\circ} \mathrm{C}$. The (C)2010 Bangladesh Uni. of Engg. $\mathcal{E}$ Tech. 
dry biomass was crushed into granules, sieved to different particle sizes, and then preserved in desiccators for use.

\subsection{Preparation of synthetic solutions}

A stock solution of $500 \mathrm{mg} \mathrm{L}^{-1}$ was prepared by dissolving the appropriate amount of MR (obtained from s.d.Fine Chemicals, Mumbai, India) in $100 \mathrm{~mL}$ and made to 1000 $\mathrm{mL}$ with distilled water. Different concentrations ranged between 25 and $200 \mathrm{mg} \mathrm{L}^{-1}$ of MR were prepared from the stock solution. All the chemicals used throughout this study were of analytical-grade reagents. Double-distilled water was used for preparing all of the solutions and reagents. The initial $\mathrm{pH}$ was adjusted with $0.1 \mathrm{M} \mathrm{HCl}$ or $0.1 \mathrm{M} \mathrm{NaOH}$. All the adsorption experiments were carried out at room temperature $\left(27 \pm 2^{\circ} \mathrm{C}\right)$.

\subsection{Batch adsorption studies}

\subsubsection{Effect of $\mathrm{pH}$ on $\mathrm{MR}$ adsorption}

The effect of $\mathrm{pH}$ on the equilibrium uptake of dyes was investigated by employing an initial concentration of MR $(100 \mathrm{mg} / \mathrm{L})$ and $0.6 \mathrm{~g} / 50 \mathrm{~mL}$ of CAS. The initial $\mathrm{pH}$ values were adjusted with $0.1 \mathrm{M} \mathrm{HCl}$ or $\mathrm{NaOH}$ to form a series of $\mathrm{pH}$ from 2 to 10 . The suspensions were shaken at room temperature $\left(27 \pm 2^{\circ} \mathrm{C}\right)$ using agitation speed $(150 \mathrm{rpm})$, the minimum contact time required to reach the equilibrium (100 $\mathrm{min}$ ) and the amount of MR adsorbed determined.

\subsubsection{Effect of CAS dose on MR adsorption}

The effect of adsorbent dose on the equilibrium uptake of MR (100 mg L $\mathrm{m}^{-1}$ ) was investigated with CAS concentrations of $0.2,0.4$ and $0.6 \mathrm{~g} / 50 \mathrm{~mL}$. The experiments were performed by shaking known MR concentration with the above different CAS concentrations to the equilibrium uptake (100 min) and the amount of MR adsorbed was determined.

\subsubsection{Kinetics studies}

Adsorption studies were conducted in $250-\mathrm{mL}$ shaking flasks at a solution $\mathrm{pH}$ of 7.0 . CAS $(0.2 \mathrm{~g} / 50 \mathrm{~mL})$ was thoroughly mixed individually with $50 \mathrm{~mL}$ of MR solution (100 $\mathrm{mg} / \mathrm{L}$ ) and the suspensions were shaken at room temperature. Samples of $1.0 \mathrm{~mL}$ were collected from the duplicate flasks at required time intervals viz.10, 20,30,40,50,60,70,80,90 and100 min and were centrifuged for $5 \mathrm{~min}$. The clear solutions were analyzed for residual MR concentration in the solutions.

\subsubsection{Adsorption isotherm}

Batch adsorption experiments were carried out in a rotary shaker at $150 \mathrm{rpm}$ using $250 \mathrm{ml}$-shaking flasks at room temperature for $100 \mathrm{~min}$. The CAS $(0.2$ and $0.6 \mathrm{~g})$ was thoroughly mixed with $50 \mathrm{~mL}$ of MR solutions. The isotherm studies were performed by varying the initial MR concentrations from 25 to $200 \mathrm{mg} / \mathrm{L}$ at $\mathrm{pH}$ 7.0, which was adjusted using $0.1 \mathrm{M} \mathrm{HCl}$ or $0.1 \mathrm{M} \mathrm{NaOH}$ before addition of CAS and maintained throughout the experiment. After shaking the flasks for $100 \mathrm{~min}$, the reaction mixture was analyzed for the residual MR concentration.
The concentration of MR in solution was measured by using direct UV-vis spectrophotometric method using a Systronic Spectrophotometer-104 at wavelength of $540 \mathrm{~nm}$. All the experiments were duplicated and only the mean values are reported. The maximum deviation observed was less than $\pm 4 \%$.

Adsorption of MR from simulated wastewater was studied using $0.2 \mathrm{~g} / 50 \mathrm{~mL}$ of CAS and MR concentrations $100 \mathrm{mg}$ $/ \mathrm{L}$ at initial $\mathrm{pH}$ 7.0. The amount of dye adsorbed at equilibrium onto carbon, $q_{e}(\mathrm{mg} / \mathrm{g})$, was calculated by the following mass balance relationship:

$$
q_{e}=\left(C_{0}-C_{e}\right) V / W
$$

where $C_{0}$ and $C_{e}(\mathrm{mg} / \mathrm{L})$ are the initial and equilibrium liquid-phase concentration of MR, respectively, $V$ is the volume of the solution(L), and $W$ is the weight of the CAS used(g).

\section{Results and Discussion}

\subsection{Effect of system $\mathrm{pH}$ on MR Uptake}

The $\mathrm{pH}$ of the system exerts profound influence on the adsorptive uptake of adsorbate molecules presumably due to its influence on the surface properties of the adsorbent and ionization/dissociation of the adsorbate molecule. Figure 1 shows the variations in the removal of dye from wastewater at different system $\mathrm{pH}$. From the figure, it is evident that the maximum removal of MR color is observed at $\mathrm{pH} 4$. Similar trend of $\mathrm{pH}$ effect was observed for the adsorption of MR on activated carbon prepared from sugarcane bagasse [19], and cucumis sativa [20], which may be attributed to the hydrophobic nature of the developed carbon which led to absorb hydrogen ions $\left(\mathrm{H}^{+}\right)$onto the surface of the carbon when immersed in water and made it positively charged. Low $\mathrm{pH}$ value (1.0 to 3.0) leads to an increase in $\mathrm{H}^{+}$ion concentration in the system and the surface of the activated carbon acquires positive charge by absorbing $\mathrm{H}^{+}$ions. On the other hand, increase of the $\mathrm{pH}$ value led to increase of the number of negatively charged sites. As the CAS surface is negatively charged at high $\mathrm{pH}$, a significantly strong electrostatic attraction appears between the negatively charged carbon surface

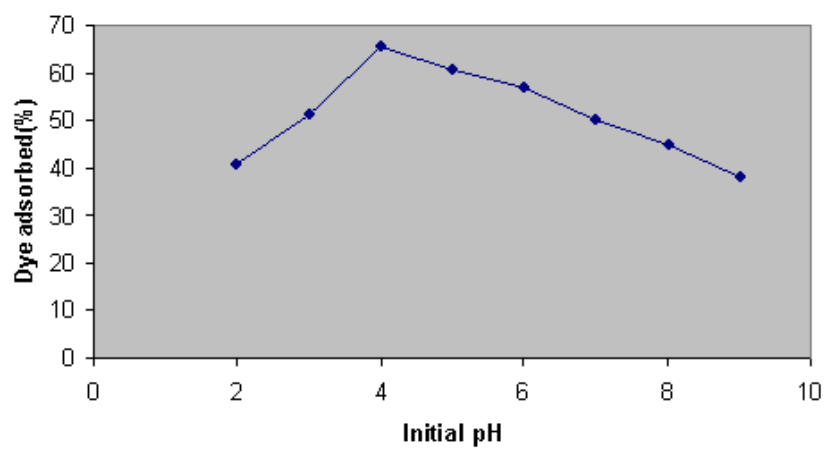

Figure 1: Effect of system $\mathrm{pH}$ on adsorption of MR $\left(100 \mathrm{mg} \mathrm{L}^{-1}\right)$ onto CAS $(0.6 \mathrm{~g} / 50 \mathrm{~mL})$ at room temperature $\left(27 \pm 2{ }^{\circ} \mathrm{C}\right)$, agitation speed $150 \mathrm{rpm}$ for the minimum contact time required to reach the equilibrium $(100 \mathrm{~min})$ 
and cationic dye molecule leading to maximum adsorption of cationic dyes [21] from waste water. The lowest adsorption occurred at $\mathrm{pH} 2.0$ and the highest adsorption occurred at $\mathrm{pH} \sim 6.0$. Adsorbents surface would be positively charged up to $\mathrm{pH}<4$, and heterogeneous in the $\mathrm{pH}$ range 4-6. Thereafter, it should be negatively charged. Moreover, the increasing in the adsorption of MR with decreasing of $\mathrm{pH}$ value is also due to the attraction between azo dye and excess $\mathrm{H}^{+}$ions in the solution.

\subsection{Effect of contact time and initial MR concentration}

The relation between removal of MR and reaction time were studied to see the rate of dye removal. The results of percentage removal of $\mathrm{MR}$ at $\mathrm{pH} 4.0$ with increase of contact time using CAS are presented in Figure 2. It was found that more than 50\% removal of MR concentration occurred in the first $50 \mathrm{~min}$, and thereafter the rate of adsorption of the MR onto CAS were found to be slow. The rapid adsorption at the initial contact time is due to the highly negatively charged surface of the CAS for adsorption of MR in the solution at $\mathrm{pH} 4$. Later slow rate of MR adsorption is probably due to the electrostatic hindrance or repulsion between the adsorbed negatively charged adsorbate species onto the surface of CAS and the available adsorbate species in the solution as well as the slow pore diffusion of the solute ions into the bulk of the adsorbent. The equilibrium was attained at 100 min when the maximum MR adsorption onto CAS was reached.

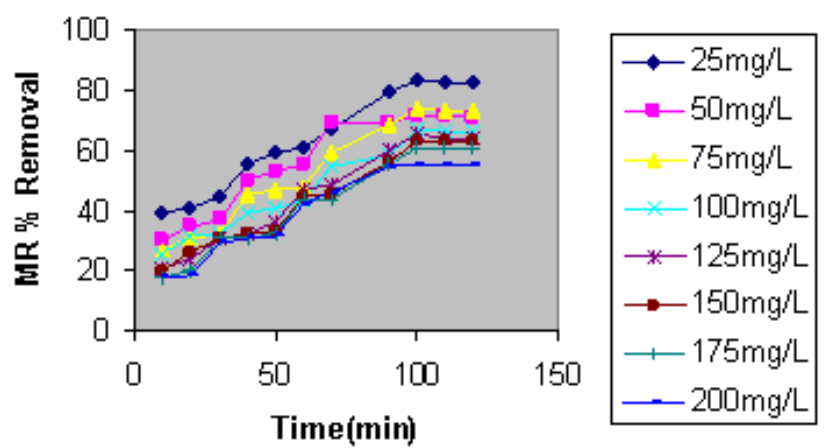

Figure 2: Effect of contact time on the removal of different initial concentrations of MR using CAS $(0.2 \mathrm{~g} / 50 \mathrm{~mL})$ at $\mathrm{pH} 4.0$

Also, the effect of initial concentration of MR in the solution on the capacity of adsorption onto CAS was studied and is shown in Figure 2. The experiments were carried out at fixed adsorbent dose $(0.2 \mathrm{~g} / 50 \mathrm{~mL})$ in the test solution at room temperature $\left(27 \pm 2^{\circ} \mathrm{C}\right), \mathrm{pH} 4$ and at different initial concentrations of MR $(25,50,75,100,125,150,175$ and $\left.200 \mathrm{mg} \mathrm{L}^{-1}\right)$ for different time intervals $(10,20,30,40,50$, $60,70,80,90$ and $100 \mathrm{~min}$ ). Figure 2 shows that the percentage of adsorption efficiency of CAS decreased with the increase of initial MR concentration in the solution. Though the percent adsorption decreased with increase in initial dye concentration, the actual amount of MR adsorbed per unit mass of adsorbent increased with increase in MR concentration in the test solution.
It is evident from Figure 2 that the amount adsorbed on the solid phase CAS at a lower initial concentration of MR was smaller than the corresponding amount when higher initial concentrations were used. However, the percentage removal of MR was greater at lower initial concentrations and smaller at higher initial concentrations. The adsorption capacity for CAS was increased from 5.176 to $27.68 \mathrm{mg} \mathrm{g}^{-1}$ as the MR concentration increased from 25 to $200 \mathrm{mg} \mathrm{L}^{-1}$. In the process of MR adsorption initially dye molecules have to first encounter the boundary layer effect and then it has to diffuse from boundary layer film onto adsorbent surface and then finally, it has to diffuse into the porous structure of the adsorbent. This phenomenon will take relatively longer contact time.

\subsection{Effect of adsorbent mass on MR adsorption}

The adsorption of MR on CAS was studied by changing the quantity of adsorbent $(0.2,0.3,0.4,0.5$ and $0.6 \mathrm{~g} / 50 \mathrm{~mL})$ in the test solution while keeping the initial MR concentration $\left(100 \mathrm{mg} \mathrm{L}^{-1}\right)$, temperature $\left(27 \pm 2^{\circ} \mathrm{C}\right)$ and $\mathrm{pH}(4.0)$ constant at contact times for $100 \mathrm{~min}$ (Figure 3). The adsorption increased from $66.67 \%$ to $75.86 \%$, as the CAS dose increased from $0.2 \mathrm{~g}$ to $0.6 \mathrm{~g} / 50 \mathrm{~mL}$ at equilibrium time $(100$ min). Maximum MR removal was achieved within 10-50 min after which MR concentration in the reaction solution was almost constant. Increase in the adsorption with adsorbent dose can be attributed to increased MR surface area and availability of more adsorption sites, while the unit adsorbed of MR decreased with increase in CAS dose.

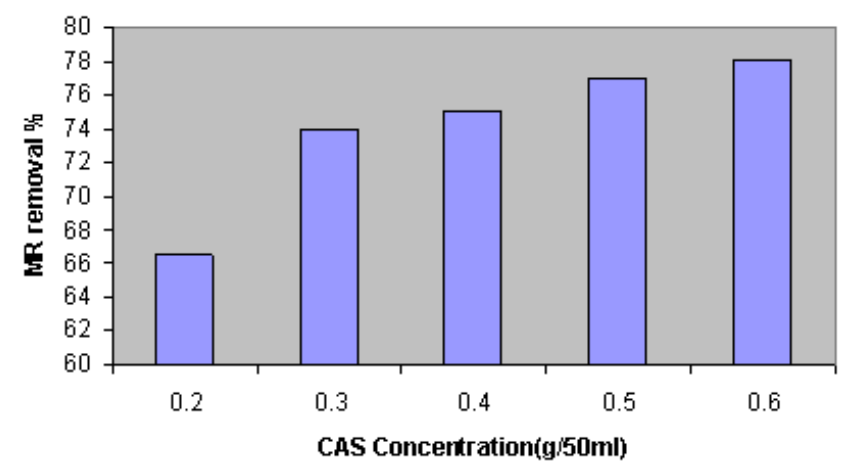

Figure 3: Effect of adsorbent concentration on MR removals (C0: $100 \mathrm{mg}$ $\mathrm{L}^{-1}, \mathrm{pH} 4.0$, agitation speed: $150 \mathrm{rpm}$, temperature: $27 \pm 2^{\circ} \mathrm{C}$ )

\subsection{Isotherm data analysis}

The relationship between the amount of a substance adsorbed at constant temperature and its concentration in the equilibrium solution is called the adsorption isotherm. The adsorption isotherm is important from both a theoretical and a practical point of view. In order to optimize the design of an adsorption system to remove the dye, it is important to establish the most appropriate correlations of the equilibrium data of each system. Equilibrium isotherm equations are used to describe the experimental adsorption data. The parameters 
obtained from the different models provide important information on the adsorption mechanisms and the surface properties and affinities of the adsorbent. The most widely accepted surface adsorption models for single-solute systems are the Langmuir and Freundlich models. The correlation with the amount of adsorption and the liquid-phase concentration was tested with the Langmuir, Freundlich, Tempkin and Dubinin-Radushkevich (D-R) isotherm equations. Linear regression is frequently used to determine the best-fitting isotherm, and the applicability of isotherm equations is compared by judging the correlation coefficients.

\subsubsection{Langmuir isotherm}

The theoretical Langmuir isotherm [22] is valid for adsorption of a solute from a liquid solution as monolayer adsorption on a surface containing a finite number of identical sites. Langmuir isotherm model assumes uniform energies of adsorption onto the surface without transmigration of adsorbate in the plane of the surface [23]. Therefore, the Langmuir isotherm model was chosen for estimation of the maximum adsorption capacity corresponding to complete monolayer coverage on the adsorbent surface. The Langmuir nonlinear equation is commonly expressed as followed:

$$
q_{e}=\frac{Q_{m} K_{a} C_{e}}{1+K_{a} C_{e}}
$$

where, $Q_{m}$ is a constant and reflect a complete monolayer $\left(\mathrm{mg} \mathrm{g}^{-1}\right) ; K_{a}$ is adsorption equilibrium constant $\left(\mathrm{L} \mathrm{mg}^{-1}\right)$ that is related to the apparent energy of sorption. The Langmuir isotherm Equation 2 can be linearized [24, 25], as shown in Equation 3.

$$
\frac{C_{e}}{q_{e}}=\frac{1}{K_{a} Q_{m}}+\frac{1}{Q_{m}} \times C_{e}
$$

A plot of $C_{e} / q_{e}$ versus $C_{e}$ should indicate a straight line of slope $1 / Q_{m}$ and an intercept of $1 /\left(K_{a} Q_{m}\right)$. The results obtained from the Langmuir model for the removal of MR onto CAS are shown in Table 1. The correlation coefficients reported in Table 1 showed strong positive evidence on the adsorption of MR onto CAS follows the Langmuir isotherm. The applicability of the linear form of Langmuir model to CAS was proved by the high correlation coefficients $R^{2}>0.95$. This suggests that the Langmuir isotherm provides a good model of the sorption system. The maximum monolayer capacity $Q_{m}$ obtained from the Langmuir is $40.486 \mathrm{mg} \mathrm{g}^{-1}$.

\subsubsection{The Freundlich isotherm}

The Freundlich isotherm model [25] is the earliest known equation describing the adsorption process. It is an empirical equation and can be used for non-ideal sorption that involves heterogeneous adsorption. The Freundlich isotherm can be derived assuming a logarithmic decrease in the enthalpy of adsorption with the increase in the fraction of occupied sites and is commonly given by the following non-linear equation:

$$
q_{e}=K_{F} C_{e}^{1 / n}
$$

Table 1: Comparison of the coefficients isotherm parameters for MR adsorption onto CAS (CAS concentration: $0.2 \mathrm{~g} / 50 \mathrm{ml}$ )

\begin{tabular}{ll}
\hline \multicolumn{2}{l}{ Langmuir: } \\
$Q_{m}\left(\mathrm{mgg}^{-1}\right)$ & 40.486 \\
$K_{a}\left(\mathrm{~L}^{-1}\right)$ & 0.0248 \\
$R^{2}$ & 0.9491 \\
\hline Freundlich: & \\
$1 / n$ & 0.5931 \\
$K_{F}\left(\mathrm{mg}^{-1}\right)$ & 2.0583 \\
$R^{2}$ & 0.9396 \\
\hline Tempkin: & \\
$\alpha\left(\mathrm{L}^{-1}\right)$ & 0.2032 \\
$\beta\left(\mathrm{mg}^{-1}\right)$ & 8.0501 \\
$b$ & 309.83 \\
$R^{2}$ & 0.9386 \\
\hline Dubinin-Radushkevich: & \\
$Q_{m}\left(\mathrm{mg}^{-1}\right)$ & 25.134 \\
$K\left(\times 10^{-5} \mathrm{~mol}^{2} \mathrm{~kJ}^{-2}\right)$ & 0.04 \\
$E\left(\mathrm{kJmol}^{-1}\right)$ & 0.118 \\
$R^{2}$ & 0.9203 \\
\hline
\end{tabular}

where $K_{F}$ is a constant for the system, related to the bonding energy. $K_{F}$ can be defined as the adsorption or distribution coefficient and represents the quantity of dye adsorbed onto adsorbent for unit equilibrium concentration. $1 / n$ is indicating the adsorption intensity of dye onto the adsorbent or surface heterogeneity, becoming more heterogeneous as its value gets closer to zero. A value for $1 / n$ below 1 indicates a normal Langmuir isotherm while $1 / n$ above 1 is indicative of cooperative adsorption. Equation 4 can be linearized in the logarithmic form (Equation 5) and the Freundlich constants can be determined:

$$
\log q_{e}=\log K_{F}+\frac{1}{n} \log C_{e}
$$

The applicability of the Freundlich adsorption isotherm was also analyzed, using the same set of experimental data, by plotting $\log q_{e}$ versus $\log C_{e}$. The data obtained from linear Freundlich isotherm plot for the adsorption of the MR onto CAS is presented in Table 1. The correlation coefficients $(>0.94)$ showed that the Freundlich model is comparable to the Langmuir model. The $1 / n$ is lower than 1.0, indicating that MR is favorably adsorbed by CAS.

\subsubsection{The Tempkin isotherm}

Tempkin adsorption isotherm model was used to evaluate the adsorption potentials of the CAS for MR. The derivation of the Tempkin isotherm assumes that the fall in the heat of adsorption is linear rather than logarithmic, as implied in the Freundlich equation. The Tempkin isotherm has commonly been applied in the following form [26-28]:

$$
q_{e}=\frac{R T}{b} \ln \left(A C_{e}\right)
$$

The Tempkin isotherm, Equation 6, can be simplified to the following equation:

$$
q_{e}=\beta \ln \alpha+\beta \ln C_{e}
$$

where $\beta=(R T) / b, T$ is the absolute temperature in Kelvin and $R$ is the universal gas constant, $8.314 \mathrm{~J}(\mathrm{~mol} \mathrm{~K})^{-1}$. The constant $b$ is related to the heat of adsorption [29, 30]. The adsorption data were analyzed according to the linear form 
of the Tempkin isotherm Equation 7. Examination of the data shows that the Tempkin isotherm fitted well the MR adsorption data for CAS. The linear isotherm constants and coefficients of determination are presented in Table 1. The correlation coefficients $R^{2}$ obtained from Tempkin model were comparable to that obtained for Langmuir and Freundlich equations, which explain the applicability of Tempkin model to the adsorption of MR onto CAS.

\subsubsection{The Dubinin-Radushkevich (D-R) isotherm}

The D-R model was also applied to estimate the porosity apparent free energy and the characteristics of adsorption [31-33]. The D-R isotherm dose not assumes a homogeneous surface or constant adsorption potential. The D-R model has commonly been applied in the following Equation 8 and its linear form, Equation 9.

$$
\begin{aligned}
q_{e} & =Q_{m} \exp \left(-K \varepsilon^{2}\right) \\
\ln q_{e} & =\ln Q_{m}-K \varepsilon^{2}
\end{aligned}
$$

where $K$ is a constant related to the adsorption energy, $Q_{m}$ is the theoretical saturation capacity, $\varepsilon$ is the Polanyi potential, calculated from Eq. (10).

$$
\varepsilon=R T \ln \left(1=\frac{1}{C_{e}}\right)
$$

The slope of the plot of $\ln q_{e}$ versus $\varepsilon^{2}$ gives $K\left(\mathrm{~mol}^{2} \mathrm{~kJ}^{-2}\right)$ and the intercept yields the adsorption capacity, $Q_{m}\left(\mathrm{mg} \mathrm{g}^{-1}\right)$. The mean free energy of adsorption $(E)$, defined as the free energy change when one mole of ion is transferred from infinity in solution to the surface of the solid, was calculated from the $K$ value using Equation 11[34]:

$$
E=\frac{1}{\sqrt{2 K}}
$$

The calculated value of D-R parameters is given in Table 1 . The saturation adsorption capacity $Q_{m}$ obtained using D-R isotherm model for adsorption of MR onto CAS is $25.134 \mathrm{mg} \mathrm{g}^{-1}$ at $0.2 \mathrm{~g} / 50 \mathrm{~mL}$ adsorbent dose, which is close to that obtained $\left(18.38 \mathrm{mg} \mathrm{g}^{-1}\right)$ from second order kinetic model (Table 2). The values of $E$ calculated using Equation 11 is $0.118 \mathrm{~kJ} \mathrm{~mol}^{-1}$, which indicating that the physicosorption process plays the significant role in the adsorption of MR onto CAS.

Table 2: Comparison of the first- and second-order adsorption rate constants and calculated and experimental $q_{e}$ values: initial MR $100 \mathrm{mg} \mathrm{L}^{-1}$ and CAS $0.2 \mathrm{~g} / 50 \mathrm{~mL}$

\begin{tabular}{c|ccc|cccc}
\hline Experimental & \multicolumn{2}{|c|}{ First-order kinetic model } & \multicolumn{4}{|c}{ Second-order kinetic model } \\
\hline$q_{e}$ & $k_{1}$ & $q_{e}$ & $R^{2}$ & $k_{2}$ & $q_{e}$ & $h$ & $R^{2}$ \\
\hline 18.713 & 0.0009 & 57.17 & 0.982 & 0.006 & 18.38 & 1.92 & 0.991 \\
\hline
\end{tabular}

\subsection{Kinetic models applied to the adsorption of MR onto CAS}

Several steps can be used to examine the controlling mechanism of adsorption process such as chemical reaction, diffusion control and mass transfer; kinetic models are used to test experimental data from the adsorption of MR onto CAS. The kinetics of MR adsorption onto CAS is required for selecting optimum operating conditions for the full-scale batch process. The kinetic parameters, which are helpful for the prediction of adsorption rate, give important information for designing and modeling the adsorption processes. Thus, the kinetics of MR adsorption onto CAS were analyzed using pseudo-first-order [35], pseudo-second-order [36], Elovich [37-39] and intraparticle diffusion [40, 41] kinetic models. The conformity between experimental data and the modelpredicted values was expressed by the correlation coefficients $\left(R^{2}\right.$, values close or equal to 1$)$. The relatively higher value is the more applicable model to the kinetics of MR adsorption onto CAS.

\subsubsection{Pseudo-first-order equation}

The adsorption kinetic data were described by the Lagergren pseudo-first-order model [35], which is the earliest known equation describing the adsorption rate based on the adsorption capacity. The differential equation is generally expresses a follows:

$$
\frac{d q_{t}}{d t}=k_{1}\left(q_{e}-q_{t}\right)
$$

where $q_{e}$ and $q_{t}$ are the adsorption capacity at equilibrium and at time $t$, respectively $\left(\mathrm{mg} \mathrm{g}^{-1}\right), k_{1}$ is the rate constant of pseudo-first-order adsorption $\left(\mathrm{L} \mathrm{min}^{-1}\right)$. Integrating Equation 12 for the boundary conditions $t=0$ to $t$ and $q_{t}=0$ to $q_{t}$ gives:

$$
\log \left(\frac{q_{e}}{q_{e}-q_{t}}\right)=\frac{k_{1}}{2.303} t
$$

Equation 13 can be rearranged to obtain the following linear form:

$$
\log \left(q_{e}-q_{t}\right)=\log \left(q_{e}\right)-\frac{k_{1}}{2.303} t
$$

In order to obtain the rate constants, the values of $\log \left(q_{e}-\right.$ $q_{t}$ ) were linearly correlated with $t$ from which $k_{1}$ and predicted $q_{e}$ can be determined from the slope and intercept of the plot, respectively (Figure 4). The variation in rate should be proportional to the first power of concentration for strict

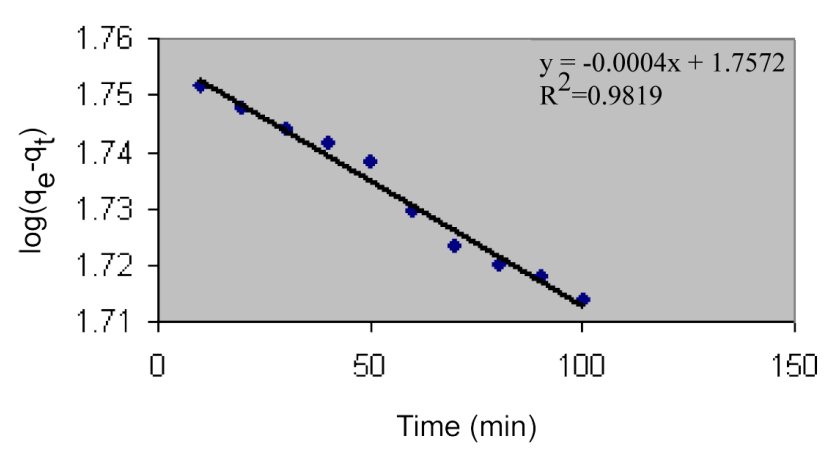

Figure 4: Pseudo-first-order kinetics for MR $\left(100 \mathrm{mg} \mathrm{L}^{-1}\right)$ adsorption onto CAS. Conditions: adsorbent dosage $0.2 \mathrm{~g} / 50 \mathrm{~mL}, \mathrm{pH} 4.0$, temperature $27 \pm 2^{\circ} \mathrm{C}$ 
surface adsorption. However, the relationship between initial solute concentration and rate of adsorption will not be linear when pore diffusion limits the adsorption process. Figure 4 shows that the pseudo-first-order equation fits well for the first $50 \mathrm{~min}$ and thereafter the data deviate from theory. Thus, the model represents the initial stages where rapid adsorption occurs well but cannot be applied for the entire adsorption process. Furthermore, the correlation coefficient $R^{2}$ are relatively low for most adsorption data and the adsorption maximum obtained was differ from the experimental value (Table 2). This shows that the adsorption of MR onto CAS cannot be applied and the reaction mechanism is not a firstorder reaction.

\subsubsection{Pseudo-second-order equation}

The adsorption kinetic may be described by the pseudosecond-order model [36]. The differential equation is generally given as follows:

$$
\frac{d q_{t}}{d t}=k_{2}\left(q_{e}-q_{t}\right)^{2}
$$

where $k_{2}\left(\mathrm{~g}(\mathrm{mg} \mathrm{min})^{-1}\right)$ is the second-order rate constant of adsorption. Integrating Equation 15 for the boundary conditions $q_{t}=0$ to $q_{t}$ at $t=0$ to $t$ and rearranging gives the following linear form:

$$
\frac{t}{q_{t}}=\frac{1}{k_{2} q_{e}^{2}}+\frac{1}{q_{e}} t
$$

The second-order rate constants were used to calculate the initial sorption rate, given by the following equation:

$$
h=k_{2} q_{e}^{2}
$$

If the second-order kinetics is applicable, then the plot of $t / q_{t}$ versus $t$ should show a linear relationship. Values of $k_{2}$ and equilibrium adsorption capacity $q_{e}$ were calculated from the intercept and slope of the plot of $t / q_{t}$ versus $t$ (Figure 5). The linear plots of $t / q_{t}$ versus $t$ show good agreement between experimental and calculated $q_{e}$ values at $100 \mathrm{mg} / \mathrm{L}$ initial MR and $0.2 \mathrm{mg} / 50 \mathrm{~mL}$ adsorbent concentrations (Table 2). The correlation coefficients for the second-order kinetic model are greater than 0.99 and the adsorption maximum obtained was close to the experimental value, which led to believe that the pseudo-second-order kinetic model provided good correlation for the bioadsorption of MR onto CAS. The values of initial sorption $(h)$ that represents the rate of initial adsorption, is $1.920 \mathrm{mg}(\mathrm{g} \mathrm{min})^{-1}$ with $100 \mathrm{mg} / \mathrm{L}$ MR concentrations onto CAS dose $0.2 \mathrm{~g} \mathrm{~mL}^{-1}$ (Table 2).

\subsubsection{Elovich equation}

The Elovich equation is another rate equation based on the adsorption capacity generally expressed as following [3739]:

$$
\frac{d q_{t}}{d t}=B_{E} \exp \left(-A_{E} q_{t}\right)
$$

where $B_{E}$ is the initial adsorption rate $\left(\mathrm{mg}(\mathrm{g} \mathrm{min})^{-1}\right)$ and $A_{E}$ is the de-sorption constant $\left(\mathrm{g} \mathrm{mg}^{-1}\right)$ during any experiment.

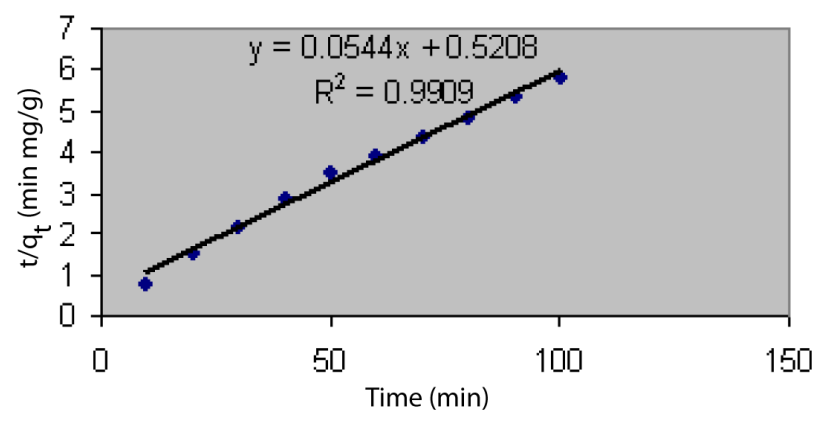

Figure 5: Pseudo-second-order kinetics for MR (100 $\left.\mathrm{mg} \mathrm{L}^{-1}\right)$ adsorption onto CAS. Conditions: adsorbent dosage $0.2 \mathrm{~g} / 50 \mathrm{~mL}, \mathrm{pH} 4.0$, temperature $27 \pm 2^{\circ} \mathrm{C}$

Equation 18 can be simplified by assuming $A_{E} B_{E} t \gg t$ and by applying the boundary conditions $q_{t}=0$ at $t=0$ and $q_{t}=q_{t}$ at $t$

$$
q_{t}=\frac{1}{A_{E}} \ln \left(B_{E} A_{E}\right)+\frac{1}{A_{E}} \ln (t)
$$

If MR adsorption by CAS fits the Elovich model, a plot of $q_{t}$ versus $\ln (t)$ should yield a linear relationship with a slope of $1 / A_{E}$ and an intercept of $1 / A_{E} \ln \left(A_{E} B_{E}\right)$ (Figure 6). Thus, the constants can be obtained from the slope and the intercept of the straight line (Table 3 ). The initial adsorption rate $B_{E}$ was $33.26 \mathrm{mg}(\mathrm{g} \mathrm{min})^{-1}$ for initial MR concentration $100 \mathrm{mg}$ $\mathrm{L}^{-1}$ on CAS dose of $0.2 \mathrm{~g} \mathrm{~mL}^{-1}$. The desorption constant, $A_{E}$ was $0.4346 \mathrm{~g} \mathrm{mg}^{-1}$ for initial MR concentration $100 \mathrm{mg}$ $\mathrm{L}^{-1}$ over CAS dose of $0.2 \mathrm{~g} \mathrm{~mL}^{-1}$ (Table 3 ).

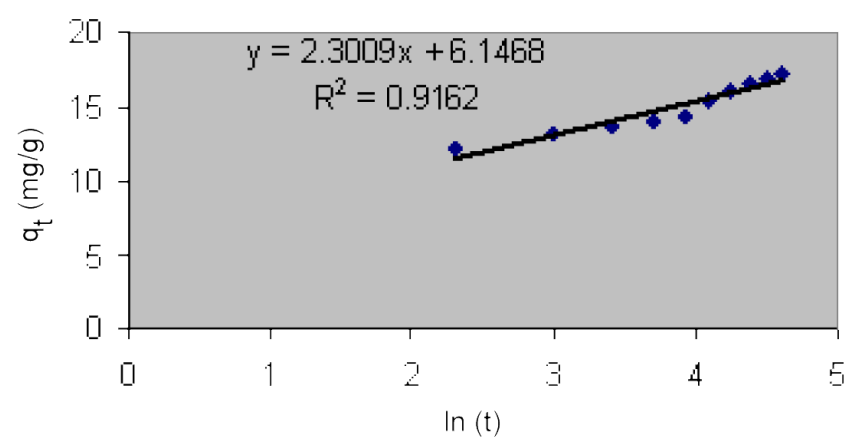

Figure 6: Elovich model plot for MR (100 $\left.\mathrm{mg} \mathrm{L}^{-1}\right)$ adsorption onto CAS Conditions: adsorbent dosage $0.2 \mathrm{~g} / 50 \mathrm{~mL}, \mathrm{pH} 4.0$, temperature $27 \pm 2^{\circ} \mathrm{C}$

Table 3: Parameters obtained from Elovich kinetics model and intraparticle diffusion model using initial MR concentration $100 \mathrm{mg} \mathrm{L}^{-1}$

\begin{tabular}{ccc|ccc}
\hline \multicolumn{3}{c|}{ Elovich } & \multicolumn{3}{c}{ Intraparticle diffusion } \\
\hline$A_{E}$ & $B_{E}$ & $R^{2}$ & $K_{\text {dif }}$ & $C$ & $R^{2}$ \\
\hline 0.43 & 33.26 & 0.917 & 0.78 & 9.408 & 0.974 \\
\hline
\end{tabular}

\subsubsection{The intraparticle diffusion model}

The adsorbate species are most probably transported from the bulk of the solution into the solid phase through intraparticle diffusion/transport process, which is often the ratelimiting step in many adsorption processes, especially in a 
rapidly stirred batch reactor [42]. Since the MR are probably transported from its aqueous solution to the CAS by intraparticle diffusion, so the intraparticle diffusion is another kinetic model should be used to study the rate of MR adsorption onto CAS. The possibility of intraparticular diffusion was explored by using the intraparticle diffusion model, which is commonly expressed by the following equation:

$$
q_{t}=K_{\mathrm{dif}}^{1 / 2}+C
$$

where $\mathrm{C}\left(\mathrm{mg} \mathrm{g}^{-1}\right)$ is the intercept and $K_{\text {dif }}$ is the intraparticle diffusion rate constant (in $\mathrm{mg} \mathrm{g}^{-1} \mathrm{~min}^{-1 / 2}$ ). The values of $q_{t}$ were found to be linearly correlated with values of $t^{1 / 2}$ (Figure 7) and the rate constant $K_{\text {dif }}$ directly evaluated from the slope of the regression line (Table 3). The value of intercept $C$ (Table 3) provide information about the thickness of the boundary layer, the resistance to the external mass transfer increase as the intercept increase. The constant $C$ was found to be 9.4084 for the dye concentration $100 \mathrm{mg} \mathrm{L}^{-1}$, which indicating the increase of the thickness of the boundary layer and decrease of the chance of the external mass transfer and hence increase of the chance of internal mass transfer. The $R^{2}$ values given in Table 3 are close to unity indicating the application of this model. This may confirm that the rate-limiting step is the intraparticle diffusion process. The intraparticle diffusion rate constant, $K_{\text {dif }}$, was $0.7758 \mathrm{~g}$ $\mathrm{g}^{-1} \mathrm{~min}^{-1 / 2}$. The linearity of the plots demonstrated that intraparticle diffusion played a significant role in the uptake of the adsorbate by adsorbent. However, As still there is no sufficient indication about it, Ho [43] has shown that if the intraparticle diffusion is the sole rate-limiting step, it is essential for the $q_{t}$ versus $t^{1 / 2}$ plots to pass through the origin, which is not the case in Figure 7, it may be concluded that surface adsorption and intraparticle diffusion were concurrently operating during the MR and CAS interactions.

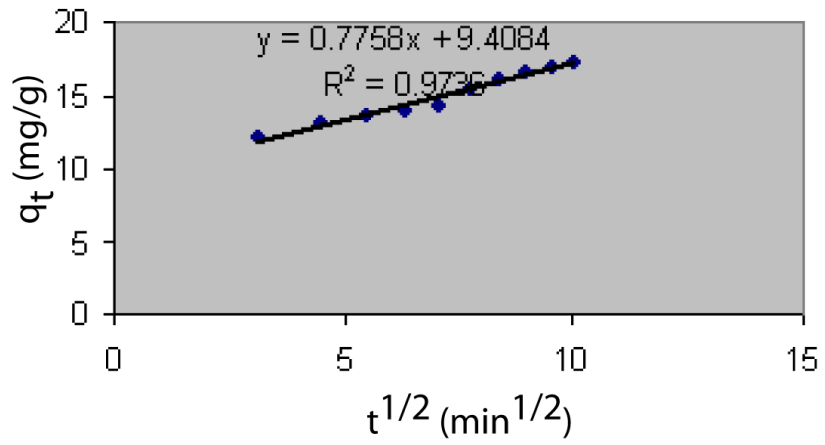

Figure 7: Intraparticle diffusion plot for MR $\left(100 \mathrm{mg} \mathrm{L}^{-1}\right)$ adsorption onto CAS. Conditions: adsorbent dosage $0.2 \mathrm{~g} / 50 \mathrm{~mL}, \mathrm{pH} 4.0$, temperature $27 \pm 2^{\circ} \mathrm{C}$

\section{Conclusion}

The results of this investigation show that activated carbon developed from Annona squmosa seed has a suitable adsorption capacity for the removal of MR from aqueous solutions. The equilibrium adsorption is practically achieved in $100 \mathrm{~min}$. The experimental results were analyzed by using Langmuir, Freundlich, Tempkin and DubininRadushkevich isotherm models and the correlation coefficients for Langmuir, Freundlich, Tempkin and DubininRadushkevich equations are well fitted. Adsorption behavior is described by a monolayer Langmuir-type isotherm. The kinetic study of MR on CAS was performed based on pseudo-first-order, pseudo-second-order, Elovich and intraparticle diffusion equations. The data indicate that the adsorption kinetics follow the pseudo-second-order rate with intraparticle diffusion as one of the rate determining steps. The present study concludes that the CAS could be employed as low-cost adsorbents as alternatives to commercial activated carbon for the removal of color and dyes from water and wastewater.

\section{References}

[1] Crini G, Non-conventional low-cost adsorbents for dye removal: A review, Bioresource Technology, 2006. 97(9):pp. 1061-1085. doi : 10.1016/j.biortech.2005.05.001

[2] Robinson T, McMullan G, Marchant R and Nigam P, Remediation of dyes in textile effluent: a critical review on current treatment technologies with a proposed alternative, Bioresource Technology, 2001. 77(3):pp. 247-255. doi : 10.1016/S0960-8524(00) 00080-8

[3] Aksu Z, Application of biosorption for the removal of organic pollutants: a review, Process Biochemistry, 2005. 40(3-4):pp. 997-1026. doi:10.1016/j.procbio.2004.04.008

[4] Han R, Zhang J, Zou W, Shi J and Liu H, Equilibrium biosorption isotherm for lead ion on chaff, Journal of Hazardous Materials, 2005. 125(1-3):pp. 266-271. doi : 10.1016/j . jhazmat.2005.05.031

[5] Gupta VK, Ali I, Suhas and Mohan D, Equilibrium uptake and sorption dynamics for the removal of a basic dye (basic red) using low-cost adsorbents, Journal of Colloid and Interface Science, 2003. 265(2):pp. 257-264. doi:10.1016/S0021-9797 (03)00467-3

[6] Ho YS, Chiu WT and Wang CC, Regression analysis for the sorption isotherms of basic dyes on sugarcane dust, Bioresource Technology, 2005. 96(11):pp. 1285-1291. doi:10.1016/j.biortech. 2004.10.021

[7] Kumar KV, Comparative analysis of linear and non-linear method of estimating the sorption isotherm parameters for malachite green onto activated carbon, Journal of Hazardous Materials, 2006. 136(2):pp. 197-202. doi:10.1016/j.jhazmat.2005.09.018

[8] Ho YS, Second-order kinetic model for the sorption of cadmium onto tree fern: A comparison of linear and non-linear methods, Water Research, 2006. 40(1):pp. 119-125. doi:10.1016/j . watres. 2005. 10.040

[9] Han R, Wang Y, Zou W, Wang Y and Shi J, Comparison of linear and nonlinear analysis in estimating the Thomas model parameters for methylene blue adsorption onto natural zeolite in fixed-bed column, Journal of Hazardous Materials, 2007. 145(1-2):pp. 331-335. doi : $10.1016 / j$.jhazmat. 2006.12.027

[10] Kumar U and Bandyopadhyay M, Sorption of cadmium from aqueous solution using pretreated rice husk, Bioresource Technology, 2006. 97(1):pp. 104-109. doi : 10.1016/j. biortech. 2005.02.027

[11] Ghimire KN, Inoue K, Miyajima T, Yoshizuka K and Shoji T, Adsorption of Some Metal Ions and Mineral Acids on Chitin, Chitin and Chitosan Research, 2001. 7(2):pp. 61-68

[12] Dhakal RP, Ghimire KN, Inoue K, Yano M and Makino K, Acidic polysaccharide gels for selective adsorption of lead (II) ion, Separation and Purification Technology, 2005. 42(3):pp. $219-225$. doi : 10.1016/j.seppur.2004.07.016

[13] Kumar KV, Optimum sorption isotherm by linear and non-linear methods for malachite green onto lemon peel, Dyes and Pigments, 2007. 74(3):pp. 595 - 597. doi:10.1016/j.dyepig. 2006.03.026

[14] Gong R, Zhang X, Liu H, Sun Y and Liu B, Uptake of cationic dyes from aqueous solution by biosorption onto granular kohlrabi peel, Bioresource Technology, 2007. 98(6):pp. 1319 - 1323. doi: $10.1016 / j$.biortech.2006.04.034 
[15] Husseien M, Amer AA, El-Maghraby A and Taha NA, Utilization of Barley Straw as a Source of a Activated Carbon for Removal of Methylene Blue from Aqueous Solution, Journal of Applied Sciences Research, 2007. 3(11):pp. 1352-1358

[16] Pramanpol N and Nitayapat N, Adsorption of Reactive Dye by Eggshell and Its Membrane, The Kasetsart Journal, 2006. 40(SI):pp. 192-197

[17] Santhi T and Manonmani S, Removal of methylene blue from aqueous solution by bioadsorption onto Recinus communis epicarp activated carbon, Chemical Engineering Research Bulletin, 2009. 13(1):pp. 15. doi:10.3329/cerb.v13i1.2518

[18] Santhi T and Manonmani S, Uptake of cationic dyes from aqueous solution by bioadsorption using granulized Annona squmosa, E-Journal of Chemistry, 2009. 6(4):pp. 1260-1266

[19] Abdullah A, Salleh M, Mazlina M, Noor M, Osman M, Wagiran R and Sobri S, Azo dye removal by adsorption using waste biomass: sugarcane bagasse, International Journal of Engineering and Technology, 2005. 2(1):pp. 8-13

[20] Santhi T, Manonmani S, Smitha T, Sugirtha D and Mahalakshmi K, Uptake of cationic dyes from aqueous solution by bioadsorption onto granular Cucumis sativa, Journal of Applied Sciences in Environmental Sanitation, 2009. 4:pp. 29-35

[21] Nemr AE, Abdelwahab O, El-Sikaily A and Khaled A, Removal of direct blue-86 from aqueous solution by new activated carbon developed from orange peel, Journal of Hazardous Materials, 2009. 161(1):pp. 102-110. doi:10.1016/j.jhazmat.2008.03.060

[22] Langmuir I, The Constitution and Fundamental Properties of Solids and Liquids. Part I. Solids, Journal of the American Chemical Society, 1916. 38(11):pp. 2221-2295. doi:10.1021/ja02268a002

[23] Doğan M, Alkan M and Onganer Y, Adsorption of Methylene Blue from Aqueous Solution onto Perlite, Water, Air, \& Soil Pollution, 2000. 120(3):pp. 229-248. doi : 10.1023/A : 1005297724304

[24] Kinniburgh DG, General purpose adsorption isotherms, Environmental Science \& Technology, 1986. 20(9):pp. 895-904. doi:10.1021/ es00151a008

[25] Longhinotti E, Pozza F, Furlan L, Sanchez M, Klug M, Laranjeira M and Fávere V, Adsorption of anionic dyes on the biopolymer chitin, Journal of the Brazilian Chemical Society, 1998. 9:pp. 435-440

[26] Aharoni C and Sparks DL, Kinetics of Soil Chemical Reactions - a Theoretical Treatment, SSSA special publication series, 1991. 27:pp. $1-18$

[27] Aharoni C and Ungarish M, Kinetics of activated chemisorption. Part 2. Theoretical models, Journal of the Chemical Society, Faraday Transactions 1: Physical Chemistry in Condensed Phases, 1977. 73:pp. 456-464. doi:10.1039/F19777300456

[28] Wang Xs and Qin Y, Equilibrium sorption isotherms for of $\mathrm{Cu}^{2+}$ on rice bran, Process Biochemistry, 2005. 40(2):pp. 677-680. doi: 10 . 1016/j.procbio. 2004.01 .043

[29] Akkaya G and Özer A, Biosorption of Acid Red 274 (AR 274) on Dicranella varia: Determination of equilibrium and kinetic model parameters, Process Biochemistry, 2005. 40(11):pp. 3559-3568. doi : 10.1016/j.procbio.2005.03.048

[30] Pearce CI, Lloyd JR and Guthrie JT, The removal of colour from textile wastewater using whole bacterial cells: a review, Dyes and Pigments, 2003. 58(3):pp. 179-196. doi:10.1016/S0143-7208(03) 00064-0

[31] Dubinin MM, The Potential Theory of Adsorption of Gases and Vapors for Adsorbents with Energetically Nonuniform Surfaces., Chemical Reviews, 1960. 60(2):pp. 235-241. doi :10.1021/cr60204a006

[32] Dubinin M, Modern state of the theory of volume filling of micropore adsorbents during adsorption of gases and steams on carbon adsorbents, Zhurnal Fizicheskoi Khimii, 1965. 39:pp. 1305-1317

[33] Radushkevich L, Potential theory of sorption and structure of carbons, Zhurnal Fizicheskoi Khimii, 1949. 23:pp. 1410-1420

[34] Kundu S and Gupta A, Investigations on the adsorption efficiency of iron oxide coated cement (IOCC) towards As(V)-kinetics, equilibrium and thermodynamic studies, Colloids and Surfaces A: Physicochemical and Engineering Aspects, 2006. 273(1-3):pp. 121-128. doi: $10.1016 /$ j.colsurfa.2005.08.014

[35] Lagergren S, Zur theorie dersogenannten adsorption geloster stoffe kungliga svenska vetenskapsakademiens, Handlingar, 1898. 24:pp. 139

[36] Ho, Ho YS, McKay, McKay G, Wase, Wase DAJ, Forster and Forster
CF, Study of the Sorption of Divalent Metal Ions on to Peat, Adsorption Science \& Technology, 2000. 18(7):pp. 639-650. doi: 10.1260/0263617001493693

[37] Chien SH and Clayton WR, Application of Elovich Equation to the Kinetics of Phosphate Release and Sorption in Soils, Soil Science Society of America Journal, 1980. 44(2):pp. 265-268

[38] Sparks DL, Soil Physical Chemistry, Ch. Kinetics of Reaction in Pure and Mixed Systems, CRC Press, 1986

[39] Zeldowitsch J, Über den mechanismus der katalytischen oxidation von $\mathrm{CO}$ an $\mathrm{MnO}_{2}$, Acta Physicochim URSS, 1934. 1:pp. 364-449

[40] Weber W and Morris J, Kinetics of adsorption on carbon from solution, Journal of the Sanitary Engineering Division, ASCE, 1963. 89(17):pp. 31-60

[41] Srinivasan K, Balasubramanian N and Ramakrishna T, Studies on chromium removal by rice husk carbon, Indian journal of environmental health, 1988. 30(4):pp. 376-387

[42] McKay G, The adsorption of dyestuffs from aqueous solution using activated carbon: Analytical solution for batch adsorption based on external mass transfer and, The Chemical Engineering Journal, 1983. 27(3):pp. 187-196. doi : 10.1016/0300-9467 (83) 80075-6

[43] Ho YS, Removal of copper ions from aqueous solution by tree fern, Water Research, 2003. 37(10):pp. 2323-2330. doi:10.1016/ S0043-1354(03)00002-2 